\title{
The knowledge and attitude of medicine students towards stem cells application and donation in neurologic disorders: A study at Guilan University of Medical Sciences, Iran
}

\author{
Farnaz Salahizadeh Baghmisheh', Amaneh Mohammadi Roushandeh², Sajjad Rezaei, \\ Alia Sabari ${ }^{4}$, Zahra Gholipour Soleimani ${ }^{5}$ \\ ${ }^{1}$ Neuroscience Research Center, Poursina Hospital, Faculty of Medicine, Guilan University of Medical Sciences, Guilan, Iran \\ ${ }^{2}$ Cellular and molecular Research Center, Medicine Faculty, Guilan University of Medical Sciences, Rasht, Iran \\ ${ }^{3}$ Department of Psychology, University of Guilan, Rasht, Iran \\ ${ }^{4}$ Neuroscience Research Center Neurology Department, Poursina Hospital, Guilan University of Medical Sciences, \\ Guilan, Iran \\ ${ }^{5}$ Neuroscience Research Center Nursing Department, Poursina Hospital, Guilan University of Medical Sciences, Guilan, Iran
}

\begin{abstract}
Background. Medical students have a significant role in improving new perspective about stem cell application in treatment of incurable diseases; such as degenerative neurologic disorders.

Methods. In this descriptive cross-sectional study conducted in 2019-2020, 424 medical students at Guilan University of Medical Sciences responded to a questionnaire. The questionnaire was included the questions about knowledge of medical students about application of stem cells in neurologic disorders and stem cells donation and their attitude as well. Exclusion criteria were reluctance to participate in study and less than $20 \%$ response to questionnaire. The convenience sampling method was used. Inclusion criteria were being a medical student and willingness to participate in the project. Data were analyzed using SPSS 20 by Pearson correlation, independent student t, one-way ANOVA, U-Mann-Whitney. Results. $49.5 \%$ and $43.2 \%$ of participants had very low and low knowledge about using the stem cell. The higher score of knowledge was related to higher education periods. $70.3 \%$ of medical students had moderate attitude toward using stem cell. Only $17 \%$ of them had known the state agencies and private centers of donation. $70.5 \%$ had moderate knowledge and $55.2 \%$ had moderate attitude toward the stem cell donation. There was a correlation between the knowledge and attitude toward its donation $(p=0.004, r=0.14)$. Knowledge about stem cells donation had correlation with the knowledge about its application ( $p=0.001, r=0.161)$.

Conclusion. Although the majority of medical students have very low knowledge about stem cell application in treatment of neurologic disorders, but their attitude toward using stem cell was moderate.
\end{abstract}

Keywords: stem cells, knowledge, attitude, neurologic diseases, medical students

\section{INTRODUCTION}

Stem cell therapy, as a novel therapeutic strategy has been started recently in Iran. Stem cells are characterized for their potency in self renewing and capacity in regeneration and restore the dam- aged tissues. Today, stem cells capability to differentiate and regenerate into specialized cell types makes them the favorite concern in medicine and treatment of some incurable disease [1]. 
Etiology of various common neurological disorders such as Parkinson's disease (PD), stroke, multiple sclerosis (MS) etc. is based on loss of neurons. It is hoped that stem cells will also help treatment of neurologic disorder by cell replacement or neuroprotection. Both main sources of stem cells including embryonic stem cells (ESC) or other types of stem cells carving from other adult tissues such as adult central nervous system (CNS) can be used in stem-cell therapies [2,3]. Autologous hematopoietic stem cell transplantation (AHSCT) in 1997 has been tried on MS patients [4]. In the last decade, studies have been demonstrated that neurogenesis is observed in some zones of the human adult brain including dentate nucleus of the hippocampus and the sub-ventricular zone, following damage to brain such as ischemia. These new evidence provide the hopes of utilizing neurogenic stem cells in therapy of numerous neurologic disorders [5]. Potential of stem cell to restore normal function of damaged tissues and aim to achieve improvements in treatment of disabilities caused by incurable neurologic diseases, now has attracted the attention of scientists all around the world [6].

In 1991 the first hematopoietic stem cell transplantation (HSCT) had been performed in Iran. In 2009, Iranian Stem Cell Donor Registry (ISCDR) or Sepas Center (in Farsi) the first registration center of stem cells donation in Iran had been established. Two years after, it became the member of World Marrow Donor Association (WMDA). ISCDR is actually a national center of registering hematopoietic stem cell voluntary donation. At the beginning, there was just one center of ISCDR in Tehran (The capital of Iran) but currently there are more donation centers in north, west and other parts of Tehran. There is also some other provinces of Iran which has these ISCDR donors centers including Kermanshah, Tabriz and Mashhad. Iranian Blood Transfusion Organization (IBTO) has been decided to develop donor centers in all 31 provinces of Iran $[7,8]$.

As it has been described, the era of cell therapy in Iran is its infancy. There is no information about our medical student regards to knowledge and attitude about stem cells application and donation. The medical students are who contribute directly to patients and people. They can also encourage people to contribute in donating stem cells by giving them right information about the donating processes, its protocol and side effects. In this study, we evaluated the knowledge and attitude of medical students of Guilan University of Medical Sciences (GUMS) about the applications and donation of stem cell in treatment of neurologic disorders.

\section{MATERIAL AND METHODS}

The present descriptive cross-sectional study was conducted in 2019-20 at GUMS. A questionnaire had been designed by researcher. The questionnaire were included the questions about knowledge of medical students about application of stem cells in neurologic disorders and stem cells donation and their attitude as well. The content validity index (CVI) and content validity ratio (CVR) of questions were evaluated by ten expert specialists in neurology and immunology and also genetic and regenerative medicine and stem cell therapy. CVR score more than 0.62 and CVI score more than 0.79 was accepted. Sample size was calculated through a pilot study. At first the questionnaire was filled by 30 medical students. The standard deviation (SD) of knowledge part of questionnaire in both applications of stem cells in neurologic disorders and stem cells donation was significantly higher than attitude part. Therefore, it was considered for sample size calculation. Finally, 424 medical students were considered for participation in the project.

Inclusion criteria were being a medical student and willingness to participate in the project. Exclusion criteria was reluctance to participate and less than $20 \%$ response to questionnaire.

The sample were gathered by convenience sampling method. The researcher referred to faculty of medicines and academic hospitals affiliated to GUMS and wanted the medical students in different levels to fill the questionnaire.

To evaluate test-retest reliability of our own administered-questionnaire, those 30 medical students, refilled the questionnaire after three weeks. Paired t-test was done to compare the scores of the first-order test and retest, and through Pearson correlation coefficient, the correlation of these two scores was examined.

The students demographic characteristics included age, sex, academic year, type of high school (National Organization for Development of Exceptional Talents [NODET] or regular high schools), citizen of Guilan province or not, have an another academic degree in other fields, exchange student and have a history of neurologic diseases in the first and second degree families.

\section{Questionnaire}

The questionnaire were included the questions about knowledge and attitude of medical students about application and donation of stem cells in neurologic disorders.

Section A evaluated the knowledge about types of stem cells. There were 16 choices that mostly represented stem cells name. The answer of most of questions was "All of them". It is noteworthy that 16 
scores were allocated to this part i.e. each choice had 1/16 score. In some questions, just one type of stem cells was the answer and it itself had 16 score. If two types of stem cells were the answer, each of choices had 8 scores. One of the questions (Q3 of section A) had six correct answers, each of the correct type of stem cells in this question had 3 scores, and total score of this special question was 18. The range of scores was between $0-98$, and it was classified in 4 groups including; very low (0-24), low (2549), moderate (50-73) and well (74-98).

Section B evaluated the knowledge of medical students about application of stem cells. It included 11 questions with answers yes, no and I don't know. 2 scores were assigned to each correct answer; however, the wrong answers were scored as 0 . In addition, the choice "I don't know" got one score. It is noted that the range of scores was 0-22 in this section and was divided into 4 grades as very low (0-5), low (6-11), moderate (12-15) and well (16-22).

Overall, the total scores in sections A and B were 0 to 120 . In addition, the scores were ranked at 4 grades of very low (0-30), low (31-60), moderate (6191) and well (92-120).

Section $C$ evaluated the attitude toward stem cells application in treatment of neurologic disorders with 8 questions. The total score was 8 to 40 . The degree of medical students' agreement or disagreement has been calculated by 5-point Likert scale. Scores has been categorized into 4 grades of very poor attitude (8-16), poor (17-24), moderate (25-32) and excellent (33-40).

Section D Included 6 questions and evaluated the knowledge about stem cells donation. 2 scores were assigned to correct answer, 0 for wrong answer and 1 to "I don't know". The scores were graded 0 to 12 and divided into three categories of low (0-4), moderate (5-8) and well (9-12).

Section E evaluated the attitude toward the stem cells donation by four questions which have been calculated by 5-point Likert scale and its scores range from 5 to 20 .

\section{Statistical analysis}

The data were analyzed using SPSS version 16. Pearson correlation test, independent t test, oneway ANOVA, U-Mann-Whitney test and Cronbach's alpha were used to present results.

There were not a significant difference between first and second time of the test-retest $(p>0.05)$. There have been strong Pearson correlation coefficient for knowledge about stem cells application ( $\mathrm{r}$ $=0.64, \mathrm{p}<0.0001)$ and attitude toward stem cells application $(r=0.88, p<0.0001)$. The Pearson correlation coefficient was strong for knowledge and attitude about stem cells donation $(\mathrm{p}<0.001)$. So that both tools had test-retest reliability.

\section{RESULTS}

424 medical students of GUMS participated in the study (range of the age: 18 to 30 years). $52.4 \%$ of them $(n=222)$ were female. $33.5 \%(n=142)$ were in first 5 semesters of education (Basic Sciences period), $12.3 \%(n=52)$ in 6-7 semesters (physiopathology period), $25 \%(n=106)$ in 8-11semesters (externship period) and $28.5 \%(\mathrm{n}=121)$ in $12-14$ semesters (Internship period).

$55 \%$ of the students had studied at regular high schools and hometowns of most of them $(64.9 \%, \mathrm{n}=$ $275)$ were in Guilan province. Only $1.7 \%(n=7)$ of participants had previous academic education before studying medicine. $2.8 \%$ of them reported the neurologic disorders in their first-degree relatives and $21.5 \%$ of them declared that have second-degree relatives with the diseases.

The Cronbach alpha index was calculated 0.52 for section A, 0.45 for section B, 0.11 for section C, 0.09 for section D and 0.30 for section E. Although the questionnaire used in this study had acceptable content and face validity and showed excellent test-retest reliability, but its internal consistency reliability was poor. Table 1 shows the descriptive indexes of multi sectional questionnaire.

TABLE 1. Descriptive index of multi sectional questionnaire

\begin{tabular}{|l|l|l|l|l|l|l|}
\hline $\begin{array}{l}\text { Questionnaire } \\
\text { Sections }\end{array}$ & min & maxi & mean & SD & Skewness & Kurtosis \\
\hline Section A & 0.00 & 72.00 & 17.64 & 14.38 & 1.07 & 0.622 \\
\hline Section B & 4.00 & 36.00 & 14.83 & 3.23 & 0.826 & 7.26 \\
\hline Section C & 8.00 & 75.00 & 27.83 & 5.89 & 4.35 & 29.19 \\
\hline Section D & 1.00 & 15.00 & 7.00 & 2.00 & -0.002 & 0.339 \\
\hline Section E & 4.00 & 56.00 & 14.00 & 3.32 & 4.85 & 59.64 \\
\hline
\end{tabular}

According to Pearson correlation coefficient test, there was no significant correlation between age and scores of each section of questionnaire (Table 2).

TABLE 2. Pearson correlation between age and multi-sectional questionnaire

\begin{tabular}{|l|l|l|l|l|l|l|}
\hline & 1 & 2 & 3 & 4 & 5 & 6 \\
\hline 1. Age & - & & & & & \\
\hline 2. Section A & -0.14 & - & & & & \\
\hline 3. Section B & -0.17 & 0.194 & - & & & \\
\hline 4. Section C & 0.005 & 0.041 & 0.079 & - & & \\
\hline 5. Section D & -0.041 & 0.075 & 0.161 & 0.016 & - & \\
\hline 6. Section E & 0.027 & 0.035 & 0.044 & 0.140 & 0.100 & - \\
\hline
\end{tabular}

There was no significant difference between female and male students' scores in all sections of the questionnaire.

The knowledge of the students about stem cells application in neurologic disorders was depended on their year of study. The students of internship and externship periods had higher score in section $\mathrm{A}$ and $\mathrm{B}$ of questionnaire compared to students 
studying in physiopathology and basic sciences stages. The scores of students in physiopathology period were better than the students in basic sciences period. Interestingly, it has been shown that the interns had highest scores in section A and B compared to all another students that indicates their knowledge about stem cells application ( $\mathrm{F}=12.95$, $\mathrm{p}$ $<0.0001)$. However, there was no significance difference between different levels of education regard to attitude toward application of stem cells $(\mathrm{p}=$ $0.479, \mathrm{~F}=0.82$ ).

There was no significant difference between the scores of knowledge about stem cells donation $(\mathrm{F}=$ $0.05, \mathrm{p}=0.20)$ and their attitude toward stem cell donation $(\mathrm{F}=2.54, \mathrm{p}=0.56)$ regarding the years in which the students study.

Demographic characteristics including the type of high school (governmental, private or NODET), native of Guilan province or an exchange student from other universities, had no effects on scores in all sections of the questionnaire ( $p>0.05$ ).

The students who had academic degree before attending to medicine course presented the same scores compared to the students without another academic background ( $p>0.05)$.

The results of Mann-Whitney $U$ test indicated that the scores of the students who had first degree relatives with degenerative neurologic diseases were significantly higher than the other students, especially in the knowledge about stem cells application $(\mathrm{z}=2.30, \mathrm{p}=0.022)$. However, the students who had the second degree relatives with neurologic disorders had no significant difference with the other students.

The knowledge about stem cells type and other general information about stem cells application in treatment of neurologic disorders have been evaluated by two separate questionnaires. Our findings showed that 210 participants (49.5\%) earned low scores that indicate their low knowledge about stem cells. In addition, 183 participants (43.2\%) had low and 31 of them (7.3\%) represented moderate knowledge. It is noted that none of students could achieve well score. On the other hand, most of the students including $70.3 \%$ of participants had moderate attitude and $5.4 \%$ of them had strongly positive attitude toward stem cells application. $70.5 \%$ of participants had moderate knowledge and $19.3 \%$ of them achieved well scores regard to knowledge about stem cells donation. It is noteworthy that $55.2 \%$ of medical students in this study had moderate positive attitude. In addition, $1.4 \%$ of them had negative attitude regard to stem cell donation that indicates their interest in stem cell donation (Table 3).
TABLE 3. Knowledge and attitude about stem cells types and stem cells application and donation in treatment of neurologic disorders among medical students

\begin{tabular}{|l|l|l|l|}
\hline \multirow{4}{*}{$\begin{array}{l}\text { Knowledge about } \\
\text { Stem cells types } \\
\text { and stem cells } \\
\text { application }\end{array}$} & Scores level & frequency & percent \\
\cline { 2 - 4 } & low (31-60) & 183 & 49.5 \\
\cline { 2 - 4 } & moderate (61-91) & 31 & 7.3 \\
\cline { 2 - 4 } $\begin{array}{l}\text { Attitude toward } \\
\text { stem cells } \\
\text { application }\end{array}$ & Well (92-120) & 0 & 0 \\
\cline { 2 - 4 } & Very poor (8-16) & 2 & 5 \\
\cline { 2 - 4 } & Moderate(25-32) & 298 & 70.3 \\
\cline { 2 - 4 } & Excellent(33-40) & 23 & 5.4 \\
\cline { 2 - 4 } & Missed & 6 & 1.4 \\
\hline \multirow{4}{*}{$\begin{array}{l}\text { Knowledge about } \\
\text { stem cells donation }\end{array}$} & Low (0-4) & 42 & 9.9 \\
\cline { 2 - 4 } & Moderate (5-8) & 299 & 70.5 \\
\cline { 2 - 4 } & Well (9-12) & 82 & 19.3 \\
\cline { 2 - 4 } & Missed & 1 & 0.2 \\
\hline \multirow{4}{*}{$\begin{array}{l}\text { Attitude of } \\
\text { students about } \\
\text { stem cells donation }\end{array}$} & very poor (4-8) & 6 & 1.4 \\
\cline { 2 - 4 } & poor (9-12) & 126 & 29.7 \\
\cline { 2 - 4 } & moderate (13-16) & 234 & 55.2 \\
\cline { 2 - 4 } & excellent (17-20) & 57 & 13.4 \\
\cline { 2 - 4 } & missed & 1 & 2 \\
\hline
\end{tabular}

Based on the table 4 there was no correlation between knowledge and attitude about application of stem cells. Interestingly, the students had higher scores in knowledge about stem cells application, had no more positive attitude about using these cells in treatment of neurological disorders ( $p>$ 0.05).

TABLE 4. Pearson correlation between each part of knowledge and attitudes about stem cells in treatment and donation

\begin{tabular}{|l|l|l|l|l|l|l|}
\hline & 1 & 2 & 3 & 4 & 5 & 6 \\
\hline $\begin{array}{l}\text { 1. Total score } \\
\text { on stem cell } \\
\text { knowledge }\end{array}$ & - & & & & & \\
\hline $\begin{array}{l}\text { 2. Knowledge } \\
\text { about types of } \\
\text { stem cells }\end{array}$ & 0.973 & - & & & & \\
\hline $\begin{array}{l}\text { 3. Knowledge } \\
\text { about stem cells } \\
\text { application }\end{array}$ & 0.392 & 0.194 & - & & & \\
\hline $\begin{array}{l}\text { 4. Attitude } \\
\text { toward stem } \\
\text { cells application }\end{array}$ & 0.050 & 0.041 & 0.079 & - & & \\
\hline $\begin{array}{l}\text { 5. Knowledge } \\
\text { about stem cells } \\
\text { donation }\end{array}$ & 0.016 & 0.075 & 0.161 & 0.016 & - & \\
\hline $\begin{array}{l}\text { 6. Attitude of } \\
\text { students about } \\
\text { stem cells } \\
\text { donation }\end{array}$ & -0.032 & -0.035 & 0.044 & 0.14 & 0.10 & - \\
\hline
\end{tabular}

The results of Pearson correlation analysis showed that there was a strong correlation between knowledge about the application of stem cell (section B) and the total scores of knowledge about stem 
cells (section A) $(r=0.973, p=0.0001)$. There was correlation between the scores of knowledge about types of stem cells (section A) and their application in treatment of neurological disorders (section B) ( $\mathrm{r}$ $=0.194, p=0.0001)$. A moderate to weak correlation was observed between knowledge about stem cell application and the total score on stem cell knowledge $(r=0.392, p=0.0001)$. Knowledge about stem cell donation had no correlation with the total score on stem cell knowledge $(r=0.016, p>0.05)$. Knowledge about stem cells donation had weak correlation with the knowledge about stem cells application (section B) $(r=0.161, p=0.001)$. There was a weak correlation between attitude toward stem cell donation and the knowledge about stem cell donation $(\mathrm{r}=0.10, \mathrm{p}=0.039)$ and attitude toward stem cells application $(r=0.14, p=0.004)$ (Table 4).

\section{DISCUSSION}

In the present study, we revealed that MD students at GUMS represented low degree of knowledge about stem cells type and their application in treatment of neurologic disorders. Despite insufficient knowledge about stem cell types and their application in neurologic disorders, the students had high level attitude toward the stem cells application in patients and its donation.

It is noteworthy that many of students complained about not learning of stem cells in their college courses, when they were filling out the questionnaires. It is noted that the students at higher level (intern and extern) had better scores about their knowledge about stem cells. Demographic parameters had no effects on their level of knowledge about stem cells.

However, the students who had a first-degree relative with neurologic disorders represented higher scores regard to knowledge about stem cells. It is suggested that the condition provides motivation to whom to search about novel treatment including stem cells.

Kim et al. in 2016 in Malaysia conducted a similar study and found out that the knowledge of medical students about stem cells had no correlation with their university education level. They found that although Malaysian medical students had general knowledge about stem cells, they eventually know nothing about stem cells transplantation with therapeutic purposes. Also, in this study, the demographic information of the medical students, including gender, religion, race, educational level and their university, did not make a difference in the scores of knowledge about stem cells (6).

Tork et al in 2018 in Saudi Arabia, found that there was moderate levels of knowledge and positive attitude toward stem cells and their use in health care providers. The study has revealed the need of improving the knowledge and attitude stem cells toward by setting educational programs about stem cells for MD students. In their study, two questions were about the use of stem cells in the treatment of diseases such as Alzheimer's, Parkinson's, as well as paralysis and spinal cord injuries, in which only $36.4 \%$ and $41.6 \%$, answered to these two questions. In addition, the participants were asked about the source of information about stem cells, of which $39.2 \%$ stated that they had received information from conferences and only $6.8 \%$ claimed that they had information about it from their education period (1).

In the study of Jee Leng et al. in 2015, the majority of nursing students (76.1\%) had a good attitude and $15.9 \%$ of these students showed an excellent attitude towards the use of stem cells in the treatment of diseases, which is completely consistent with our study (9).

In 2015, Mohammed et al. conducted a pretest-posttest study to assess the effect of educational intervention on nurses of midwifery ward about umbilical cord blood collection and stem cell harvesting. They were evaluated with a multi-compartment questionnaire.This questionnaire was answered three months before, exactly after the training session and then three months after the training. The results showed that the nurses participated in this study had poor knowledge about stem cell and cord blood collection before the training course. The scores of the participants increased significantly exactly after the training period and after three months of this period. It was concluded that holding training classes may not only lead to more information for medical staff, but may also increase the motivation to study more and obtain more information in this field and lead to a change in misconceptions about this (10).

In is noteworthy that medical education in Iran at Medical Universities has several limitations. No educational curriculum about stem cells therapy and its applications in treatment of diseases is available. The lack of stem cell course at universities has limited the students' knowledge.

In the present study the most of the participants had moderate to well knowledge about stem cells donation. And more than half of them had moderate positive attitude toward stem cells donation. We assessed the students' knowledge about stem cell donation, regardless of the activities in national donation centers because of unfamiliarity of most of our students with public and private institutions in this field and the very small number of students were members of these institutions. Interestingly, in the donation parts of questionnaire, even the scores of students with a positive family history of 
degenerative neurologic diseases did not differ significantly from the scores of other students.

In a study by Hazzazi et al. in 2019 in Saudi Arabia, medical students' knowledge and attitudes towards stem cell transplantation were examined. Out of 800 medical students, 744 (93\%) answered the questions. $49 \%$ of students were in preclinical stages and $51 \%$ of them were in clinical stages. The mean scores of knowledge about the eligibility of stem cell donors were $37.4 \%$ and about the donation process was $23.6 \%$. Students who registered for stem cell donation scored better on the question of the need for a blood sample to register at a Saudi Arabia stem cell donation center. Also, the scores of these students in the questions related to the complications of stem cell donation were better than the students who did not enroll in these centers (11).

Narayanan et al. in USA in 2016 reported that there was correlation between knowledge about the donation and the student registered for bone marrow donation. The most of the students had knowledge about applications of stem cell and donation eligibility and process that means that they educated at university about the stem cell donation or heard before attending university. The scores of the students in this study were higher than our study that indicates the lack of presence of courses or curriculum about stem cell education (12).

Unfortunately, in Iran and many countries around the world, there is no formal course for medical students about donation, the characteristics of a person eligible for stem cell donation, complications and how to do it throughout the medical education, and virtually medical students are completely unfamiliar with the steps, harvesting methods, and stem cell extraction sources for donation. It will be possible to coordinate institutions and donation centers by holding training sessions about stem cell donation in order to increase the knowledge of medical students about their characteristics.

Iran as a developing country is going to improve their health system using novel therapeutic strategies. Many of people and even students are not aware about the eligibility and the process of the donation. Therefore, it is necessary to pave the roads to consider the courses about the stem cell application and their donation in medical education period.

\section{CONCLUSIONS}

The MD students at GUMS represented low and very low levels of knowledge about stem cells and their application in neurological disorders but most of them had moderate positive attitude toward it. Also the most of medical students had the moderate score in knowledge and attitude of about donation of stem cells in treatment of neurologic disorders.

Considering the scores of medical students participating in this study it may be concluded that in the medical education system of our country, considering these topics is essential. And due to the moderate to strong attitude of a large number of students to these topics, it is likely that there is sufficient interest and motivation to acquire more knowledge in this field among medical students. By encouraging and increasing the medical students' knowledge in this field, the new researches and projects will be organized by them and also the use of stem cell therapy in the country will grow up for treatment of different diseases especially neurologic disorders by these trained physicians in future.

Furthermore, by increasing medical students' knowledge about stem cell donation, familiarity with national institutions in this regard and improving their knowledge about the method of donation and its side effects can motivate them for stem cell donation. If the spirit of stem cell donation is instilled in them, they will later encourage others to do so with more confidence.

It is suggested that similar researches to be conducted in the students of paramedicine colleges and other non-medical students. In addition, evaluation the knowledge and attitude of students about the stem cells therapy and its donation in the treatment of neurological diseases before and after training sessions could be the future investigation.

\section{Acknowledgments}

This article is extracted from the Thesis of Farnaz Salahizadeh Baghmisheh; Faculty of Medicine, Guilan University of Medical Sciences, Guilan.

We thanks all students and professor of medical sciences who cooperate in validation and fulfilling of the questionnaires of this study.

Conflict of interest: none declared Financial support: none declared

\section{REFERENCES}

1. Tork H, Alraffaa S, Almutairi K, Alshammari N, Alharbi A, Alonzi A. Stem cells: knowledge and attitude among health care providers in Qassim region, KSA. International Journal of Advanced Nursing Studies. 2018;7(1):1-7.

2. Nisbet MC. Public opinion about stem cell research and human cloning. Public Opinion Quarterly. 2004 Mar 1;68(1):131-54.

3. Lindvall O, Kokaia Z. Stem cells for the treatment of neurological disorders. Nature. 2006 Jun;441(7097):1094-6.

4. Genc B, Bozan HR, Genc S, Genc K. Stem Cell Therapy for Multiple Sclerosis. Adv Exp Med Biol. 2019;1084:145-174.

5. Banerjee S, Williamson D, Habib N, Gordon M, Chataway J. Human stem cell therapy in ischaemic stroke: a review. Age and ageing. 2011 Jan 1;40(1):7-13.

6. Kim DL, Ramasamy TS, Amini F. Knowledge, awareness and perception of stem cells research amongst Malaysian medical students. Regenerative Research. 2016;4(2):25-30. 
7. Shaiegan M, Zolgaghari Anaraki S. Unrelated stem cell donor registries in the world and Iran. Sci J Iran Blood Transfus Organ. 2014; 11(2):164-176.

8. Pourfatollah AA. World Marrow Donor Day to Honor Stem Cell Donors in Tehran. Archives of Iranian Medicine. 2016 Dec 1;19(12):882.

9. Jee Leng LY, Lean Keng SO, Wan Amir Nizam WA, Suat Cheng TA. Knowledge and attitude about stem cells and their application in medicine among nursing students in Universiti Sains Malaysia, Malaysia. MJMS. 2015 Jul;22(4):23.

10. Mohammed HS, El Sayed HA. Knowledge and attitude of maternity nurses regarding cord blood collection and stem cells: An educational intervention. Journal of Nursing Education and Practice. 2015 Apr 1; 5(4):58.

11. Hazzazi AA, Ageeli MH, Alfaqih AM, Zakri AK, Elmakki EE. Knowledge and attitude towards hematopoietic stem cell transplantation among medical students at Jazan University, Saudi Arabia. Saudi medical journal. 2019 Oct 1;40(10):1045-51.

12. Narayanan P, Wolanskyj A, Ehlers SL, Litzow MR, Patnaik MS, Hogan WJ, Hashmi SK. Medical students' knowledge, familiarity, and attitudes towards hematopoietic stem cell donation: Stem cell donation behaviors. Biology of Blood and Marrow Transplantation. 2016 Sep 1;22(9):1710-6. 